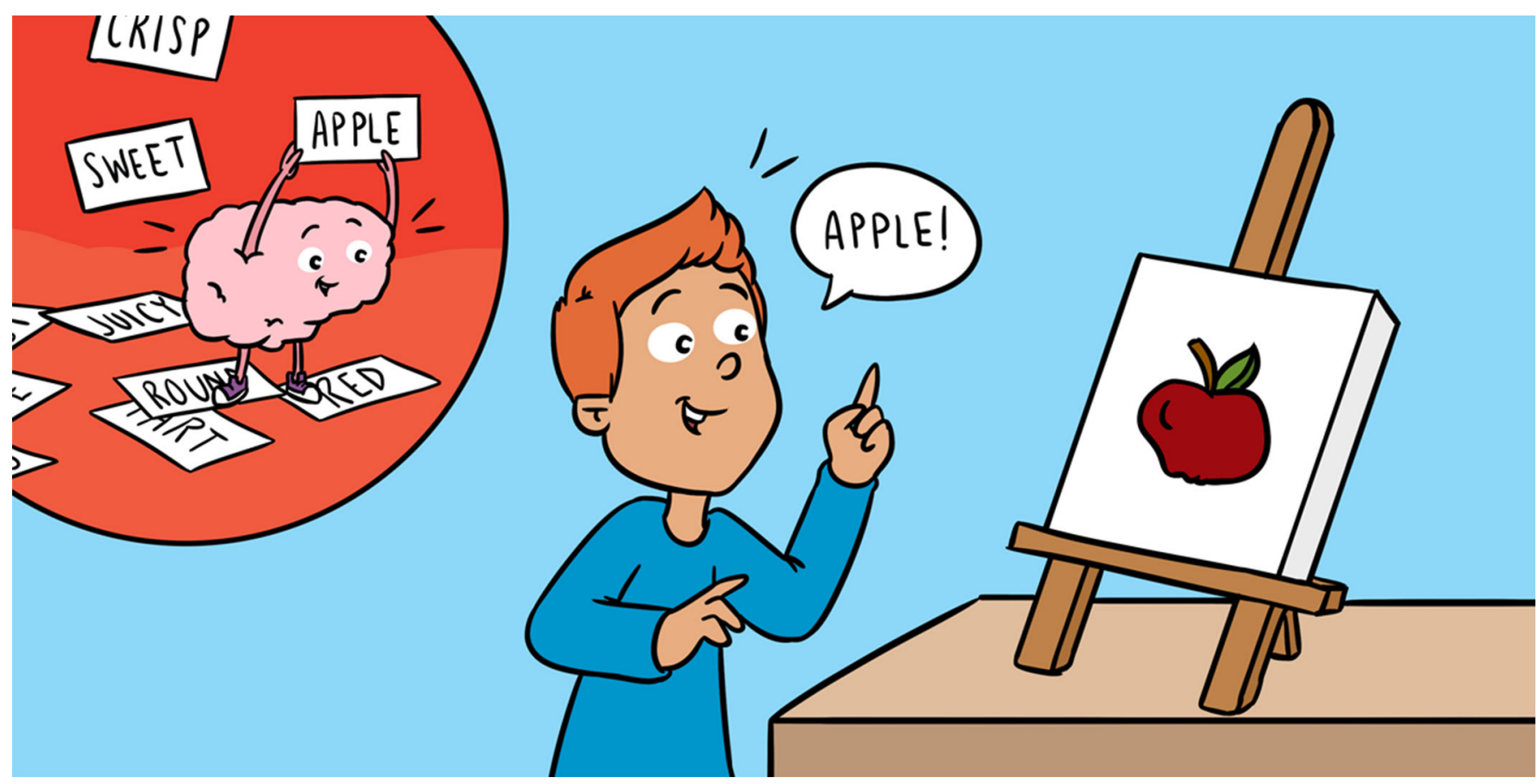

\title{
HOW DO WE CHOOSE WORDS WHEN WE SPEAK?
}

\section{Elizabeth Jane Anderson ${ }^{1}$ and Stephanie Kathleen Ries ${ }^{1,2,3 *}$}

Joint Doctoral Program in Language and Communicative Sciences, University of California, San Diego, and San Diego State University, San Diego, CA, United States

2 School of Speech, Language, and Hearing Sciences, San Diego State University, San Diego, CA, United States Center for Clinical and Cognitive Neuroscience, San Diego State University, San Diego, CA, United States

\section{YOUNG REVIEWERS:}

FLORIMONT

AGES: $15-16$
Speaking is one of the actions we do the most every day and most people are very good at it: healthy fluent speakers can easily say 2-3 words per second, selected from tens of thousands of words in our mental dictionary. The process of speaking, however, is not as simple in our brains as it seems when we are talking. Take, for example, naming a picture of an apple. Although the word apple comes easily to mind, several processes and brain regions are needed to allow us to fetch the word apple among all the words we have in our memory. Here, we studied what happens to our ability to choose words when parts of these brain regions (the left frontal cortex in particular) are damaged.

Speaking is one of the actions we do the most every day and most people are very good at it: healthy fluent speakers can easily say 2-3 words per second, selected from tens of thousands of words in our mental dictionary (over 50,000 for adults!). The process of speaking, 


\section{LEMMA}

Written language and spoken language are both made up of words. Those words can be seen and/or heard. But before we write a word down or say it out loud, it lives in the brain. Lemma is a special term for words stored in the brain.

\section{Figure 1}

This is what happens in the brain when we name a picture. First, we look at the picture and think about all the related concepts that help describe the picture. Second, we think about all the other words (lemmas) that can be described by those same concepts. Third, we select a word (lemma), with the help of an external selection mechanism (part of the brain outside of the language system that makes it easier to select words quickly), and use the brain's knowledge of phonemes to say the word out loud. however, is not as simple in our brains as it seems when we are talking. Take, for example, naming a picture of an apple. Although the word apple comes easily to mind, several processes and brain regions are needed to allow us to fetch the word apple from among all the words we have in memory. Choosing our words is just one of the steps we will describe below with the example of what our brain needs to do in order for us to name a picture of an apple.

Steps involved in choosing our words:

1. The first step is to think of the concepts associated with the picture of an apple. For example, a few concepts that are related to apples include sweet, crunchy, juicy, etc. These concepts help define what the object we see is; we can define an apple as a fruit that is sweet, crunchy, and juicy.

2. In the second step, we access all the words ${ }^{1}$ we associate with the concepts we thought of in step 1. The concepts associated with the picture of an apple can also be associated with words other than apple. Other words beside apple that might activate when we think about the concepts sweet, crunchy, juicy, etc. include pear, plum, or peach (see Figure 1).

3. The third step is word choice, during which the correct word needs to be selected from among all the activated words. This is what we are interested in researching. The brain needs to process very quickly to choose the right word during speech. Some researchers believe the language system needs help from other areas of the brain to

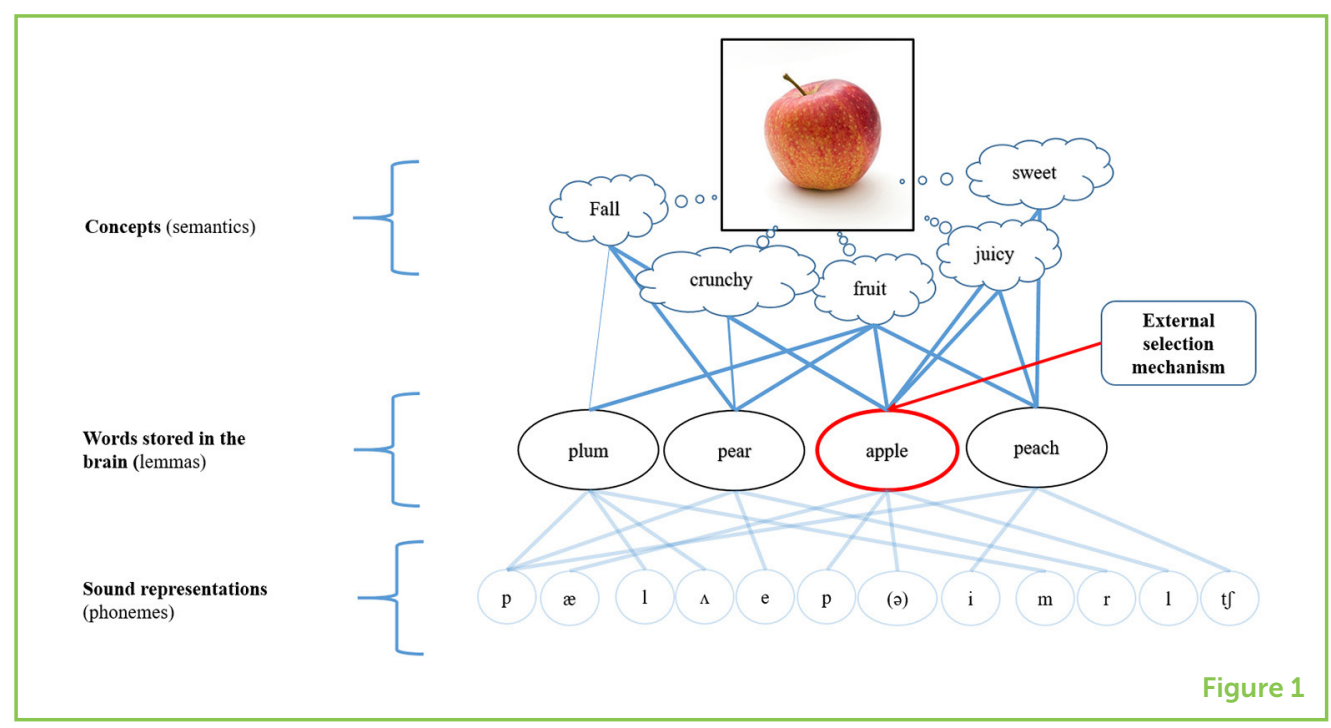

1 The technical term for words stored in the brain is lemma. See glossary for more information. 
EXTERNAL

SELECTION

\section{MECHANISM}

An external selection mechanism is a mechanism that is not directly a part of the language system but that can help the language system choose the right word when needed.

\section{PHONEME}

A phoneme is a sound we have stored in the brain. We string each phoneme (sound) together to make a whole word-a lot like spelling using the alphabet! You can think of it like this: the alphabet is for written language and phonemes are for spoken/heard language.

\section{Figure 2}

A side-view of the left half of the brain. The left prefrontal cortex, shaded in blue, and the left posterior temporal cortex, shaded in red. Both of these areas are involved in the process of speech production; they help us choose the right words to say. process and choose words so that we can speak fast enough. These proposed areas outside of the language system that help with word choice are believed to support an "external selection mechanism" (in red in Figure 1).

4. Finally, after we pick a word, we have to say it out loud. To do that, we need the fourth step. During that step, the sounds we have stored in our brain, called phonemes, need to be activated. We string each phoneme together to make a whole word. It is almost like spelling using the alphabet. You can think of it like this: the alphabet is for written language and phonemes are for spoken/ heard language.

$$
\begin{aligned}
& \text { apple-spelled with letters } \\
& \text { æpəl-spelled using phonemes }
\end{aligned}
$$

And this whole process happens so fast that you never even realize you do all these steps every time you name an object!

\section{WHICH BRAIN REGIONS HELP US CHOOSE OUR WORDS WHEN WE SPEAK?}

Several brain regions are involved with our choice of words. The two brain regions shown in Figure 2 are particularly important: the left frontal cortex (in blue) and the left posterior temporal cortex (in red). However, when the brain works well, it is sometimes difficult to know which role each of these regions plays.

Let us compare our brains to a car engine for a minute. When you look under the hood of a car, it is hard to tell what each individual part does, especially if nothing is going wrong. It looks like one big network of connected metal and wires; there is no smoke coming from anywhere

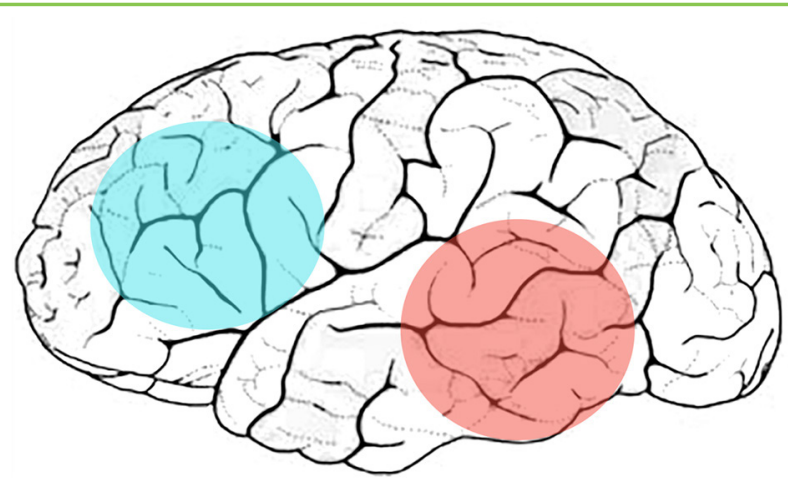

Figure 2 
telling us, "Hey, the brakes are working right now!" In the same way, it is difficult to separate which parts of the brain carry out which actions, because in a brain that is functioning normally, all of the parts are working together and doing their jobs at the same time.

To know if the different steps of the speaking process and the parts of the brain are working well, researchers can study the speed at which we can name images, as well as the number and type of errors we make. They can also use sophisticated machines and techniques to study brain activity more directly. One such technique is called functional magnetic resonance imaging ( $\mathrm{fMRI}$ ). $\mathrm{fMRI}$ lets us know that the left frontal cortex and left posterior temporal cortex are active when we choose which word to say [1]. However, even though these techniques tell us a lot about how the brain works, it is still hard to know for sure what these brain areas do without seeing what happens when they are not functioning.

\section{WHAT HAPPENS WHEN PART OF THE BRAIN DIES AFTER A STROKE?}

Sometimes, the parts of the brain necessary for using language are affected by serious health problems. Our brains need a lot of oxygen and nutrients to function. Oxygen and nutrients are brought to the brain by the blood, which runs through our arteries. Unfortunately, sometimes these arteries get clogged or break during strokes.

The areas of the brain that no longer get blood flow after a stroke experience a lack of oxygen and nutrients, so the brain tissue ends up damaged and does not work as well as it used to. After enough time without oxygen and nutrients, these brain regions will die. In 2015, there were 613,148 stroke events in the EU, and that number is projected to increase to 819,771 in 2035 [2]. This is a huge number of people! You might even know someone who had a stroke, maybe a grandparent or older relative.

When the damaged brain tissue is in the areas of the brain responsible for language, this can cause some stroke victims to struggle with language tasks that used to be very easy for them. Some people will have trouble speaking, even if they still understand what you are saying to them. Others will have trouble understanding you, but might still be able to talk, though what they say might not make a lot of sense. Stroke patients can also have a combination of trouble speaking and understanding language. Any of the steps we talked about above might be impaired, depending on which parts of the brain are damaged. 


\section{HOMOGENEOUS}

"Homo" means same.

Pictures in the

homogeneous

condition belong to the same semantic

category. For example, peach, pear, apple, and plum are all in the semantic category fruit.

\section{HETEROGENEOUS}

"Hetero" means different. Pictures in the heterogeneous condition belong to different semantic categories. For example, dog, hammer, and jacket belong to the different semantic categories animal, tool, and clothing.

\section{Figure 3}

Task 1: Blocked cyclic picture naming Task 2: Continuous picture naming. Participants see each picture one at a time and are asked to name the picture as quickly and accurately as they can. In the

heterogeneous condition participants saw pictures from different categories (for example, dog, hammer, and jacket belong to the categories animal, tool, and clothing). In the homogeneous condition participants saw pictures from the same category (for example, peach, pear, apple, and plum are all in the category fruit).
In our study, we wanted to look at word selection to see if people who had strokes affecting the left prefrontal cortex had any trouble with choosing words.

\section{DO STROKE VICTIMS HAVE MORE TROUBLE CHOOSING WORDS THAN HEALTHY PEOPLE DO?}

In this experiment [3], we tested six stroke patients with damaged tissue in the left prefrontal cortex and compared their results to those of 14 healthy adults. The healthy adults (called controls) were on average the same age and had the same amount of education as the patients, and there were the same proportion of men and women in the two groups. These precautions are important to make sure the differences we see between patients and controls are really linked to brain damage and not due to other factors, like education, age, or gender.

To test our patients' abilities to choose words, we asked them to name pictures in two different tasks:

1. In Task 1, called the blocked cyclic naming experiment, the participants had to name pictures in two different contexts [4]. We wanted to see how people with left prefrontal cortex damage could name pictures when the pictures were in the same category (for example, peach, pear, apple, and plum are all in the category fruit) vs. in different categories (for example, dog, hammer, apple, and jacket belong to the categories animal, tool, fruit, and clothing). When pictures were from the same category, we called this the homogeneous condition ("homo" means same). When pictures were from different categories, we called this the heterogeneous condition ("hetero" means different) (Figure 3, Task 1). People usually have

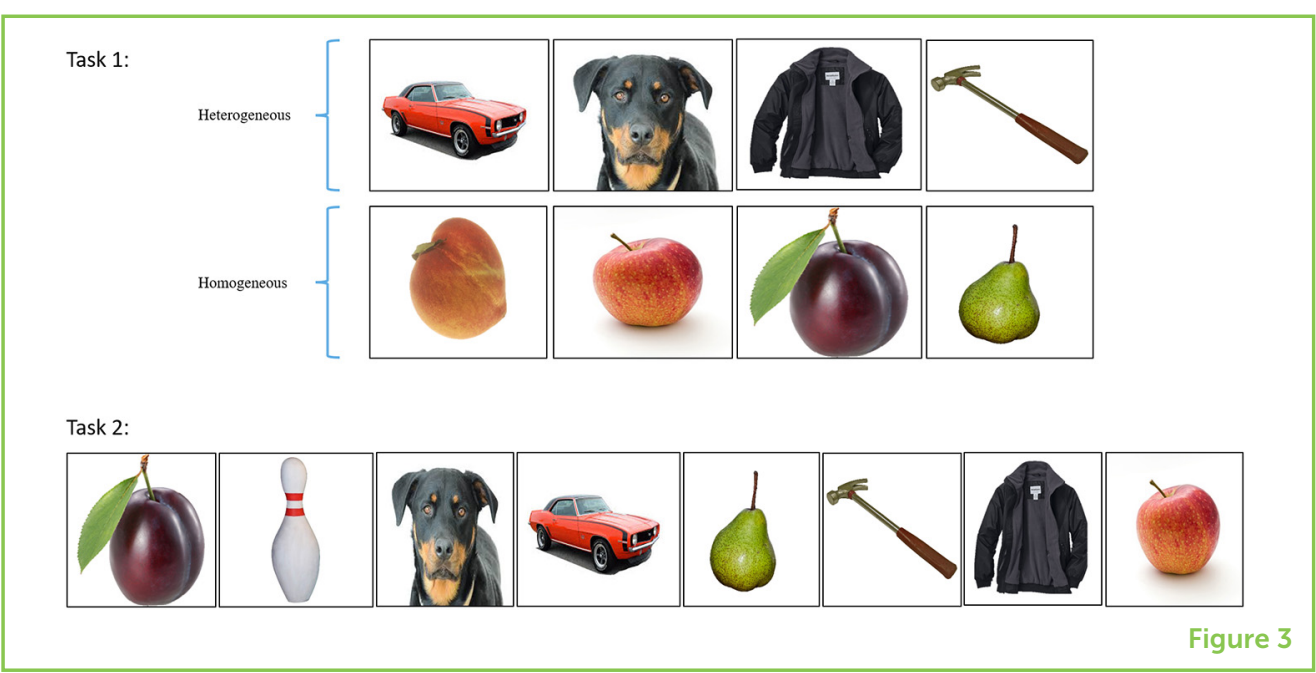




\section{SEMANTIC}

INTERFERENCE

Semantic interference is the name for the difficulty people experience when naming pictures that come from the same category. Items from the same semantic category are usually related to the same concepts, so it is harder to separate them in your mind. For example, apples and pears are both sweet crunchy, juicy fruit, so it might take you longer to tell them apart when you need to name them than it does for you to tell apart a car and a dog, which do not share any features. a harder time naming pictures in the homogeneous condition than in the heterogeneous condition. Pictures in the homogeneous condition are linked to the same concepts, so it is harder to separate them in your mind. For example, apples and pears are both sweet, crunchy, juicy fruit, so it might take you longer to tell them apart than it does for you to tell apart a car and a dog, which do not share any features.

2. In Task 2, which we call the continuous naming experiment, participants also had to name images, but these images were all mixed up together [5]. In this task, people usually take longer to name pictures in the same category when they have already seen pictures from that category before. For example, in Figure 3, Task 2, participants take longer to name apple than pear, because they have already seen two other fruits (plum and pear) instead of only one other fruit (plum). Participants slow down for apple, because the related words plum and pear (Step 2 from earlier) are still active in the brain. The brain has to work hard to ignore both of those activations and choose apple.

This difficulty people have with naming pictures that belong to the same category is called semantic interference. Semantic interference in linked to Step 3, choice of words, in both Task 1 and Task 2.

To perform these tasks, participants came to the lab and were seated comfortably in front of a computer screen. They saw the pictures appear on the screen one at a time and were asked to name pictures as fast as possible without making any mistakes. We recorded their responses with a microphone. Later, we listened to the recordings, measured how long it took participants to find the words and kept track of when they made errors. An example of an error could be if the participant called an apple a pear.

Our hypothesis was that patients with damage to the left frontal cortex would experience more semantic interference in both tasks. In Task 1, this means that the stroke patients would be slower and make more errors than the healthy control patients while naming pictures in the homogeneous vs. heterogeneous condition. In Task 2, we expected the stroke patients to be slower than the controls when naming items in the same category. For example, in Figure 3, apple would take longer to name than peach in both controls and stroke patients, but stroke patients would get even slower with each picture named in the fruit category. 


\section{HOW DID STROKE PATIENTS WITH LEFT PREFRONTAL CORTEX DAMAGE DO ON THESE TASKS?}

Both patients and controls had semantic interference in both tasks. In Task 1, both groups made more errors and took longer to name pictures in the homogeneous vs. the heterogeneous conditions. In Task 2, everyone was slower for each new image in the same semantic category.

However, in Task 1, patients with damage to the left frontal cortex had more semantic interference. When words belonged to the same category, patients were even slower and made even more errors than the controls did.

We did not see any difference between patients and controls in Task 2, meaning that damage to the left prefrontal cortex was important for word selection in Task 1 but not as important in Task 2. This could be because there is more than one way to choose a word and the different designs of the two tasks (blocked cyclic vs. continuous) caused patients' brains to use different word-choice pathways.

\section{WHAT DOES THIS MEAN FOR HOW WE USE OUR BRAINS TO CHOOSE WORDS?}

The results we found are interesting, because they show that having a damaged left frontal cortex does not always have an impact on our ability to choose words.

This likely means that, in the continuous naming experiment (Task 2), the patients' brains automatically found another way to choose words that did not rely on the left prefrontal cortex, but in the blocked cyclic picture naming (Task 1 ) they needed the left prefrontal cortex. Therefore, it looks like there may be more than one way for the brain to select a word! Sometimes we need the left prefrontal cortex and sometimes we do not. This lets us know that even if someone had a stroke that damaged the left frontal cortex, that person may still be able to select the right word when naming a picture, by using a different brain area.

The capacity that our brains have for reorganization after an injury is bewildering. Brains are very good at building new bridges once the old ones have been damaged. The next step in this field of research is to figure out what those new bridges are, that allow us to choose words after brain damage. Which brain region allows us to choose words if it is not always the left prefrontal cortex? One idea is that the left posterior temporal cortex (Figure 2, in red) may sometimes be able to help us choose words, like in Task 2. Another possibility 
is that a different brain region starts covering for the function of the damaged left prefrontal cortex. Current studies are focusing on these alternative mechanisms.

So, where does word selection take place in the brain? We still do not know for sure. That is what makes language research exciting-there is so much mystery and so much left to discover!

\section{ORIGINAL SOURCE ARTICLE}

Riès, S., Karzmark, C., Navarrete, E., Knight, R., and Dronkers, N. 2015. Specifying the role of the left prefrontal cortex in word selection. Brain Lang. 149:135-47. doi: 10.1016/j.bandl.2015.07.007

\section{REFERENCES}

1. Price, C. J. 2012. A review and synthesis of the first 20 years of PET and fMRI studies of heard speech, spoken language and reading. Neuroimage 62:816-47. doi: 10.1016/j.neuroimage.2012.04.062

2. Stevens, E., Emmett, E., Wang, Y., McKevitt, C., and Wolfe, C. 2015. Foreword. The Burden of Stroke in Europe. King's College London for Stroke Alliance for Europe (SAFE). Available online at: https://www.zdruzenjecvb.com/pdf/s8.pdf

3. Riès, S. K., Karzmark, C. R., Navarrete, E., Knight, R. T., and Dronkers, N. F. 2015. Specifying the role of the left prefrontal cortex in word selection. Brain Lang. 149:135-47. doi: 10.1016/j.bandl.2015.07.007

4. Damian, M. F., Vigliocco, G., and Levelt, W. J. M. 2001. Effects of semantic context in the naming of pictures and words. Cognition 81:B77-86. doi: 10.1016/S0010-0277(01)00135-4

5. Howard, D., Nickels, L., Coltheart, M., and Cole-Virtue, J. 2006. Cumulative semantic inhibition in picture naming: experimental and computational studies. Cognition 100:464-82. doi: 10.1016/j.cognition.2005.02.006

SUBMITTED: 09 January 2019; ACCEPTED: 15 February 2019; PUBLISHED ONLINE: 04 March 2019.

EDITED BY: Robert T. Knight, University of California, Berkeley, United States

CITATION: Anderson EJ and Ries SK (2019) How Do We Choose Words When We Speak? Front. Young Minds 7:36. doi: 10.3389/frym.2019.00036

CONFLICT OF INTEREST STATEMENT: The authors declare that the research was conducted in the absence of any commercial or financial relationships that could be construed as a potential conflict of interest. 
COPYRIGHT @ 2019 Anderson and Ries. This is an open-access article distributed under the terms of the Creative Commons Attribution License (CC BY). The use, distribution or reproduction in other forums is permitted, provided the original author(s) and the copyright owner(s) are credited and that the original publication in this journal is cited, in accordance with accepted academic practice. No use, distribution or reproduction is permitted which does not comply with these terms.

\section{YOUNG REVIEWERS}

\section{FLORIMONT, AGES: 15-16}

In our group, we reviewed the article on how we select words. We all attend Florimont school in class 2B2. Anna is petite and sporty, impulsive, and social. She was able to put her energy into the group during the review. Florence, is shy and sympathetic, and was able to apply his emotional intelligence during the review. Ketsia is energetic and also confident, and she applied her sense of humor to create a happy atmosphere in the group. Luis is creative and Pablo is calm.

\section{AUTHORS}
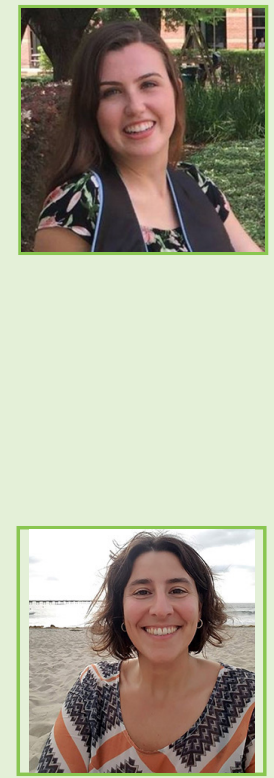

\section{ELIZABETH JANE ANDERSON}

I am a first year Ph.D. student studying Language and Communicative Disorders at both San Diego State University and University of California, San Diego. My current research looks at how our language production processes work during word selection in college-aged students without brain damage. In the future, I hope to look at language production in adults who have brain damage (like the stroke patients in this article)! When I am not studying language, I like watching movies, exploring beaches, and enjoying the sunny California weather!

\section{STEPHANIE KATHLEEN RIES}

I am an Assistant Professor in the School of Speech, Language, and Hearing Sciences at San Diego State University. I am very interested in how we use our brains to choose words when we speak, and find the brain to be a fascinating organ in general! I study language in the brain by using different techniques, such as by studying patients with brain lesions, but also by using electroencephalography and other imaging techniques. When I am not thinking or teaching about language and the brain, I enjoy spending time with my two children, Yann and Eileen, and with my husband, Vincent. *sries@sdsu.edu 